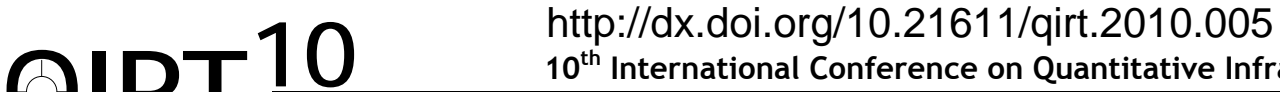 \\ $10^{\text {th }}$ International Conference on Quantitative InfraRed Thermography \\ July 27-30, 2010, Québec (Canada)
}

\section{IR Imaging for Stability Analysis Of Industrial Burner}

\author{
Allouis C.*, Pagliara R.*, Saponaro A.** \\ * Istituto di Ricerche sulla Combustione - CNR, Napoli - ITALY, allouis@irc.cnr.it \\ ** Centro di Combustione Ambientale - Gioia del Colle - ITALY
}

\begin{abstract}
In this paper, a new diagnostic tool is presented to spatially characterize combustion fluctuations. This tool based on FAst IR Imaging of flames was applied on two different types of gas turbine burners and on two traditional industrial burners varying the fluid dynamic conditions. Both GT burners evidenced oscillation at low frequencies around $25 \mathrm{~Hz}$, $100 \mathrm{~Hz}$ and at higher frequencies up to several $\mathrm{kHz}$. Typical frequencies bias toward combustion were identified. The investigations also evidenced that the typical frequencies shift up while increasing AFR. The FAIRI technique allowed to identify higher frequencies (up to several $\mathrm{kHz}$ ) in the 2D dimensions. The extension of the technique to a practical Lean Premixed gas turbine gave good results either for frequency analysis of fluctuations, either for the location of the phenomenon of humming. Regarding industrial boiler combustion the FAIRI technique allowed to identify on both gas and coal combustion the proper location of the flame root and its better performance in stability. Further information have to be collected on air/fuel mixing and local flame temperature. The technique came out as an interesting tool for further development and investigations.
\end{abstract}

\section{Introduction}

The environmental aspect becomes always more important for the development of energetic and propulsive technology; the future regulations will require a better control on the nitrogen oxides, particulate and inorganic compounds emitted from combustion sources. Fuel injection and depletion processes notably influence the formation of the pollutants in the combustion chamber and consequently their emissions. Many researches are focused on new concepts for ultra-low emissions combustors, with developments in fuel preparation and wall cooling techniques in the case of gas turbine combustors. Moreover, Coal came back as an important and challenging fuel for energy production. New burner technologies have to explored to obtain clean coal combustion in the future power plants. Concerning GT a possible technological solution for the reduction of pollution could be the use of lean mixtures premixed and prevaporized before fuel/air enter into the combustion chamber. Such a solution is the LPP (Lean Premixed Prevaporized) for liquid and LP (Lean Premixed) for gas based technologies. Nevertheless, these new emergent technologies are affected by many problems that must be solved in order to make them better reliable. Numerous experimental studies and numerical models were developed to understand the behavior of gas turbines; in particular there are current researches to understand fuel/air interaction in the premixing duct, upstream of the combustion chamber [1-4]. Indeed, the characterization of the fuel mixing with air is very important for the optimization and the choice of the injection technology, which is important since it influences the homogeneity of the fuel/air mixture. Unfortunately, developments in premixed combustion are generally accompanied by increase in occurrence of oscillating combustion [5-6]. Unstable combustion refers to self-sustained combustion oscillations at or near the acoustic frequency of the combustion chamber, which are the result of the closed-loop coupling between unsteady heat release and pressure fluctuations. The heat release fluctuations produce pressure fluctuations is well known and well understood; however, the mechanisms whereby pressure fluctuations result in a heat release fluctuations are not. Rayleigh [7] postulated that, for the pressure oscillations to be amplified, the heat release and pressure fluctuations must be in phase. The exact mechanism of unstable combustion is not yet completely understood. Moreover, in order to validate the different numerical models of combustion instabilities, real time measurements are needed giving thus the possibility of a better description of the phenomena. Acoustic frequencies can be easily measured by fast traducers, while the oscillations of the equivalence ratio can be obtain performing real time measurements [8]. Other time averaged techniques (LIF, PLIF, Chemiluminescence, etc) give an idea of the combustion process [8]. Usually, UV-Visible spectroscopy is used to obtain information on the flame structures. New available technology allows to shift the 2-dimensions studies towards the Infra Red region [9]. The objective of this paper is to test the capability of this new technique based on fast infrared imaging in individuating the flame and fluid dynamic fluctuations and the eventual correlations between them. To do that different experiments were used, a LPP burner as reference system and industrial conventional LP burner with pilot flame. In this last case, fast traducers and Fast Infra Red Imaging (FAIRI) will be used. On another hand, the capability of the FAIRI technique will be investigated on industrial burner fuelled by gas and coal to study flame stability. 


\section{Experimental Procedure}

The experiments were firstly performed using a $100 \mathrm{~kW}$ Lean Premixed Prevaporized burner fuelled with Jet-A1 fuel and using a test rig of Ansaldo Energia equipped with a $3 \mathrm{MW}$ atmospheric gas turbine burner. A sketch of the LPP burner is presented in a previous paper [9]. The swirl number of the co-rotating blades is fixed at $S=0.5$. The LPP burner was inserted in a large furnace in order to avoid acoustic interferences. Air was supplied from pressurized tanks filled by two compressors.

At CCA the Ansaldo Caldaie research combustion center, the $3 \mathrm{MW}$ test rig was used to operate the full scale turbine combustor in atmospheric condition. It is a cylindrical refractory lined combustion chamber. Particular attention have to be paid in the experimental set up design to the acoustic characteristic of the system. The rig is fully instrumented and all the operative conditions were measured and continuously registered. Fast data logging coming from pressure piezo meter was used to describe the acoustic behavior inside the combustion chamber and an FFT calculation have been performed. It is possible to say that the pilot flame fuel flow rate represents $10 \%$ of the total fuel mass flow. During our experiments it was fuelled with methane. Normal condition together with humming condition were studied. For the LLP burner, the fuel was pressurized by nitrogen in a tank before atomization in order to avoid fluctuations due to pumping. Atomization pressure was kept constant at $7 \mathrm{bar}$. Different Air/Fuel ratios (AFR), ranging between 22-30, were used for the measurements. Kerosene flow rate was kept constant at 0.5 USGal/h. The spray was generated by a hollow cone nozzle with a $60^{\circ}$ fixed angle. The combustion air was preheated at $230^{\circ} \mathrm{C}$ and regulated by a mass flow controller. The experiments were performed at atmospheric pressure for both burner types. Study were performed using a Fast InfraRed Camera in the range 1.5-5 $\mu \mathrm{m}$ (up to $30 \mathrm{kHz}$ ) with a sensor $320 \times 256$ pixels to analyze the flame fluctuations of the natural flame emission. For the LP burner fast traducers were connects to data acquisition board and Fast FFT were performed though Labview program.

A typical blue flame for stoechiometric premixed condition on LPP burner was obtained at AFR $=25$ [9].The $X-Z$ axis system is presented in figure 1 . The origin correspond to the centre of the exit plane of the mixer $(Z=0, X=0$ at the axis). For the Ansaldo burner, analysis points will be indicated in the next paragraph.

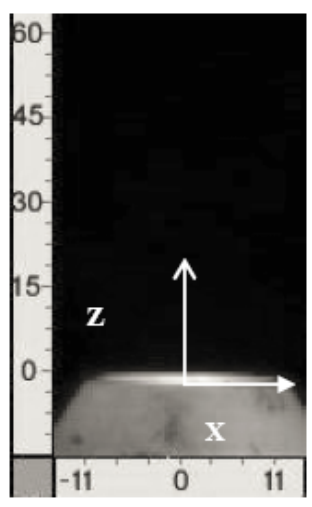

Figure 1: axis system expressed in $\mathrm{mm}$.

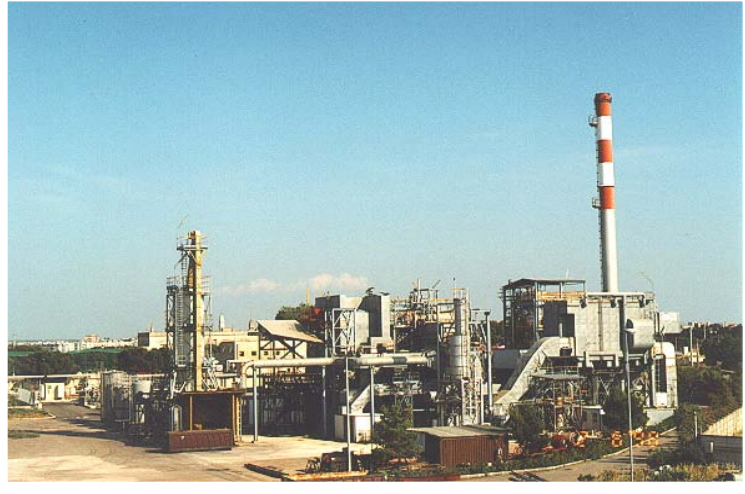

Figure 2: $50 \mathrm{MWt}$ boiler overview.

Further experiments on industrial burner were performed in a 50 MWth plant. This test rig boiler can welcome different burner types fuelled with different fuels (coal, heavy oils, etc). The $50 \mathrm{MWt}$ combustion chamber has an horizontal shape with a section of $5.5 \times 4.5 \mathrm{~m}$ and a length of $12.5 \mathrm{~m}$. an overview of the plant is presented in figure 2. The experimental boiler has several windows on its left side wall that allow an optimized view of the flame root. In the experiments two kinds of burner were used: one fuelled with natural gas alone and in blend with hydrogen, and another one fuelled with pulverized coal.

\section{Results and Discussion}

1. Results on LPP burner

The frequency analyses of complete flame (up to $100 \mathrm{~mm}$ above the burner) for the different AFR was performed using a recent available technology such as the high speed InfraRed imaging with sensor sensitivity ranging between 1.5-5 $\mu \mathrm{m}$. This technique is much more sensitive than visible CCD camera and, it is less photon demanding [9]. The image acquisitions were performed with a window size of $128 \times 18$ pixels. The frequency analysis was performed using the power spectrum of the maximum intensity included in the rectangle surface indicated on the images presented in table I. 
Table I: Spatial positions of the IR analysis.

\begin{tabular}{|c|c|c|c|}
\hline Position & Analyzed zone & $\mathrm{X}(\mathrm{mm})$ & $\mathrm{Z}(\mathrm{mm})$ \\
\hline 1 & & $0-10$ & $0-5$ \\
\hline 2 & & $0-10$ & $5-10$ \\
\hline 3 & & $0-15$ & $12-18$ \\
\hline 4 & & $0-15$ & $22-26$ \\
\hline 5 & & $0-15$ & $28-33$ \\
\hline
\end{tabular}

For more simply representation, the photographs of the flames are horizontal but the real flame is vertical. Considering past investigations [9], it was decided to limit the frequency analyses to large windows that are represented by white vertical rulers on Tab. I. The following study will concern the AFR=25. The frequency analysis under isotherm conditions is presented in figure 3 for the five positions.

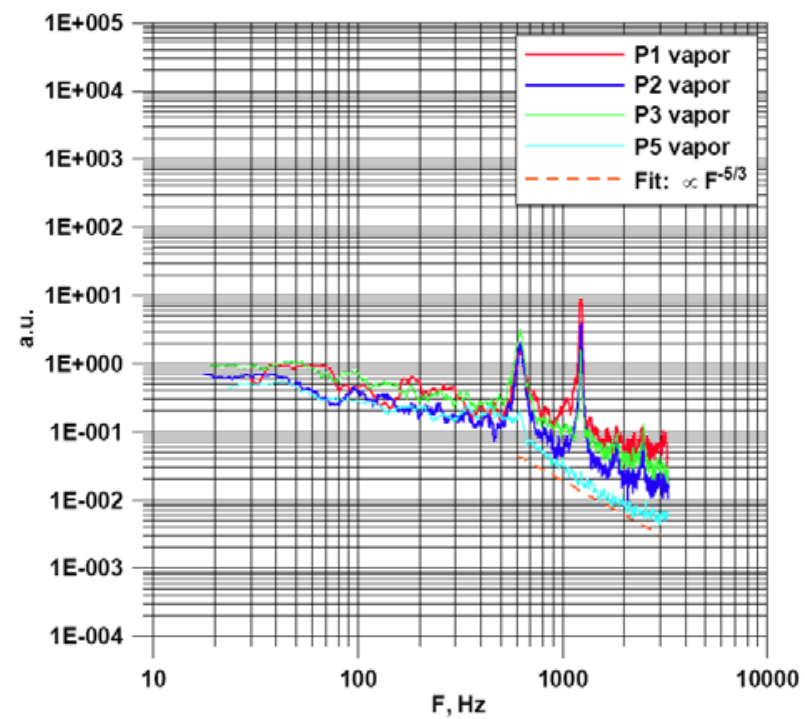

Figure 3: Frequency analysis of IR images under isotherm conditions (AFR= 25).

Position 4 is not presented since it is very close to position 3, so for clarity reason it is not showed on the figure. We clearly observe for all the positions a fundamental frequency at $\sim 620 \mathrm{~Hz}$, while its harmonics: $1240 \mathrm{~Hz}, 1850 \mathrm{~Hz}$ and $2480 \mathrm{~Hz}$ are present only for the first four positions. The intensity of the harmonics decrease when increasing height above the burner. Moreover, a fit curve is presented in the range $600-3000 \mathrm{~Hz}$ with a slope of $-5 / 3$. We can note a slope change around $600 \mathrm{~Hz}$ probably due to different phenomena. In the low frequencies zone $(<600 \mathrm{~Hz})$ the slope is $-1 / 4$ that indicates a low rate of turbulence of the system [8]. This slope could be representative of the low turbulence due to the precession visible during the experiments. Successively, frequency analysis was performed under combustion and the results are presented in figure 4. 


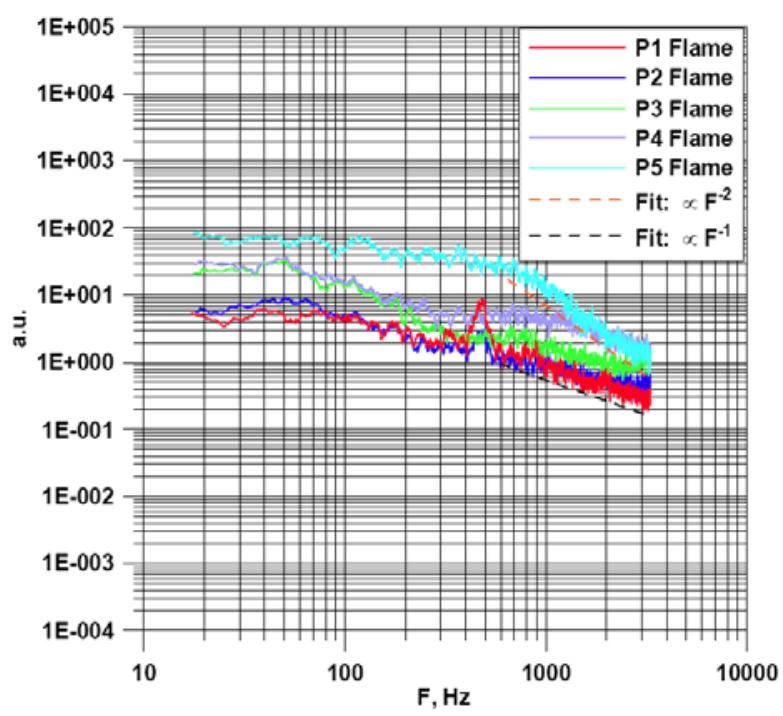

Figure 4: Frequency analysis of IR images for the different flame positions (AFR= 25).

We can observe an intense peak frequency at $\sim 480 \mathrm{~Hz}$ and some lower intense harmonics (960 $\mathrm{Hz}$ and $1920 \mathrm{~Hz})$ for the first two position, namely close to the burner exit. We can also observe minor harmonics at $120,240 \mathrm{and} 360 \mathrm{~Hz}$. These frequencies are similar to those found by Vauchelles [10] and Cabot [11]. They correlated frequencies up to $530 \mathrm{~Hz}$ to combustion phenomena. They found that the $130 \mathrm{~Hz}$ frequency is characteristic of a rich combustion regime. In fact, we observe a peak of the $130 \mathrm{~Hz}$ frequency and its harmonics in the zone close to the burner exit, namely for position 1 and 2. The combustion-biased frequency peaks become weaker when going downstream the flame. Another interesting point is the slope change after $800 \mathrm{~Hz}$ versus the position in the flame. The first two position plots show a slope of $\mathrm{F}^{-1}$, while downstream of the flame the slope can reach $\mathrm{F}^{-2}$ as shown in figure 4 . After the integrated study of the flame fluctuations for the $A F R=25$, we decided to focus the interest on the first part of the flame varying the Air Fuel ratio in order to study the fluid dynamic influence on flame fluctuation. The considered spatial position are presented in table II. The frequency analysis was performed using the power spectrum of the maximum intensity included in the black rectangle surface indicated on the images presented in table II. The results of the frequency analyses for the positions 1, 2 and 3 are presented in figure 5 .

Table II: Spatial position of the IR analysis of the different flames.

\begin{tabular}{|c|c|c|c|}
\hline Position & Flame zone analyzed & $\mathrm{X}(\mathrm{mm})$ & $\mathrm{Z}(\mathrm{mm})$ \\
\hline 1 & & 0 & 5 \\
\hline 2 & & 15 & 8 \\
\hline 3 & & 0 & 10 \\
\hline
\end{tabular}



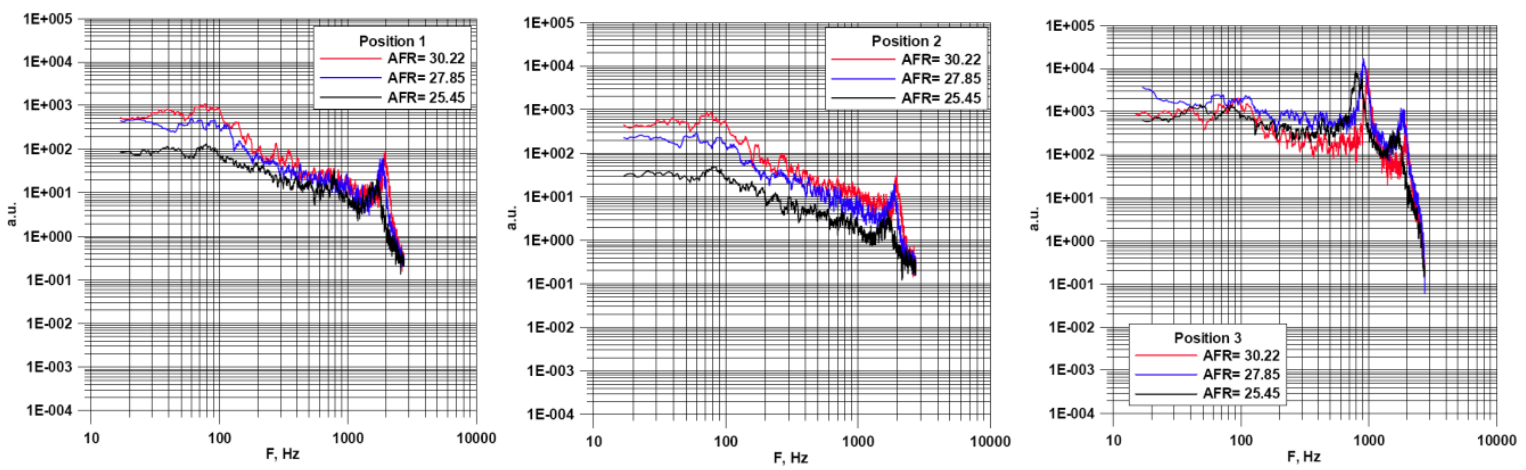

Figure 5: Frequency analysis for position 1,2 and 3.

We can notice that respect to the broad study for $A F R=25$, a narrower window size increases the precision of the spectrum and it is possible to more precisely individuate the frequency peaks. We can also observe for all the positions high peak intensity for frequencies around $2 \mathrm{kHz}$. For the positions 1 and 3 we clearly identify the lower frequency harmonics. We hypothesized that the frequency around $2 \mathrm{kHz}$ is due to fluid dynamic conditions since the frequency peak increases while increasing the air flow rate. On another hand, the presence of a second intense peak for positions 1 and 3 with a typical frequency around $900 \mathrm{~Hz}$ was also assigned to a fluid dynamic process since this frequency shifts up when increasing air flow rate. This phenomenon could represent a recirculation zone at the center of the flame. For all the positions we always observe the low frequencies biased towards combustion as explained before. They kept the same value even though the Air Fuel Ratio changed. Another interesting feature of these plots is that the slope changes versus the position in the flame. If we consider the positions 1 and 2 we have a slope of $F^{-}$ $5 / 3$ for all the AFR over the whole frequency range, while for the position 3 with have a slope of $F^{-1 / 3}$ up to $1 \mathrm{kHz}^{\text {and } \mathrm{F}^{-}}$ ${ }^{14 / 3}$ above $1 \mathrm{kHz}$. This indicates a strong turbulence change in the zone 3.

\section{Results on LP burner}

Due to the lack of optical accesses, IR Imaging was only performed together with fast traducers recording. The measurements were performed through a window situated in front of the burner at a distance of about $2 \mathrm{~m}$. The 3 investigated positions are presented in table III. Pressure oscillations and infrared images were simultaneously recorded. The position 1 represented the pilot flame, while position 2 and 3 represent respectively the secondary and the tertiary airs.

Table III: Spatial position of the IR analysis of the LP burner.

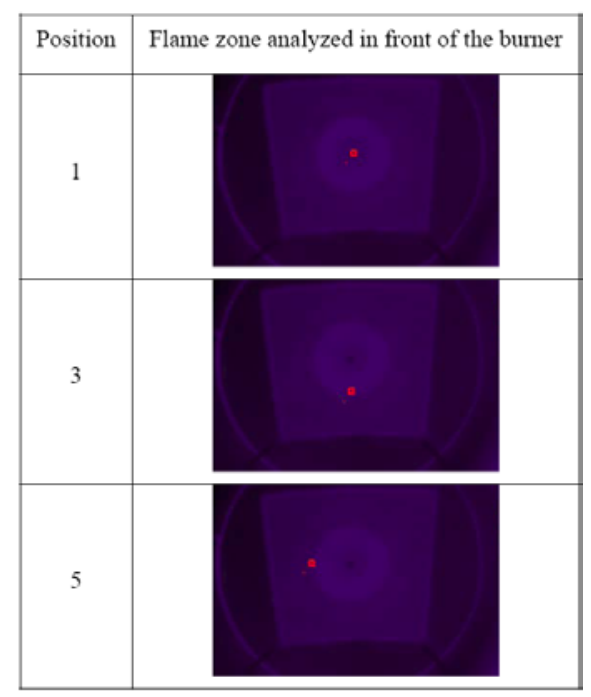


Result of FAIRI analysis is presented in figure 6 for normal combustion condition and under humming condition.

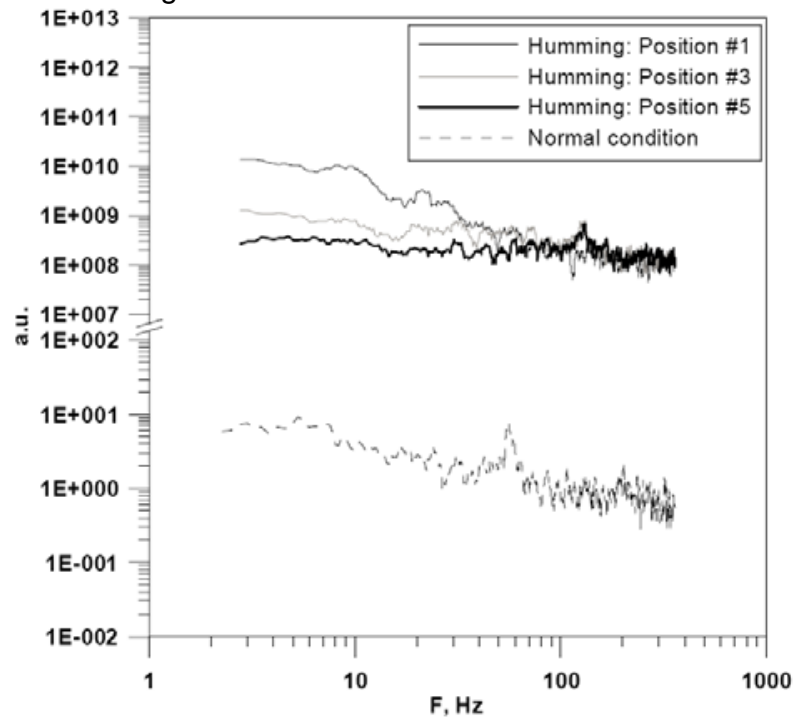

Figure 6: Frequency analysis of IR images under normal and humming conditions.

We observe than flame intensity, represented by the signal intensity background, is low under normal condition, while humming generates more intense flames. A typical frequency is found around $50-60 \mathrm{~Hz}$ under normal combustion, while humming generates frequency around $25 \mathrm{~Hz}$ and $125 \mathrm{~Hz}$. Moreover, turbulence intensity of LP burner is much lower than in the case of LPP burner. The humming phenomenon was confirmed by fast traducers records analysis presented in figure 7.

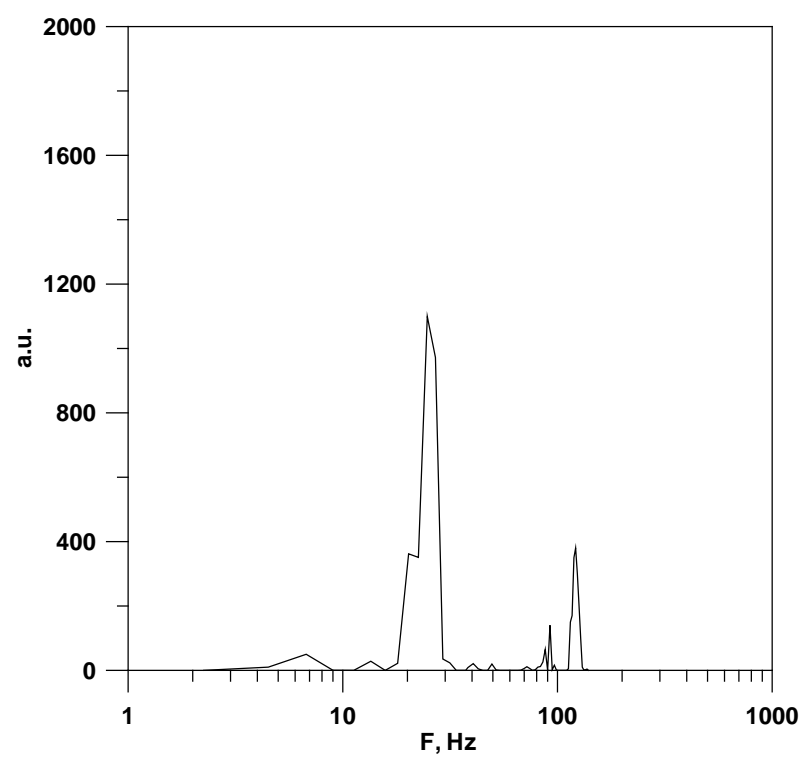

Figure 7: Frequency analysis of traducers under humming conditions.

A good agreement was found between traducer results and the Fast infrared analysis. Finally, the IR analyses allowed to spatially locate the humming phenomenon in positions \#1 and \#3, while traducers give an overall results of the presence or not of the phenomenon. 


\section{Results on traditional burners}

Two burners were studied in term of flame stability: one fuelled with natural gas (NGB), and one fuelled with coal (CB). The objective of the study was to check the flame stability while burning different fuels (methane, methane+ $\mathrm{H}_{2}$ and coal) and introducing water steam and re-circulated exhaust gases to lower emissions. The operative conditions are explained in the figure labels.

On figure 8 are presented normal and filtered IR views of the NGB. We can observe on the left side picture the red rectangle that represents the zone of interest for flame stability.
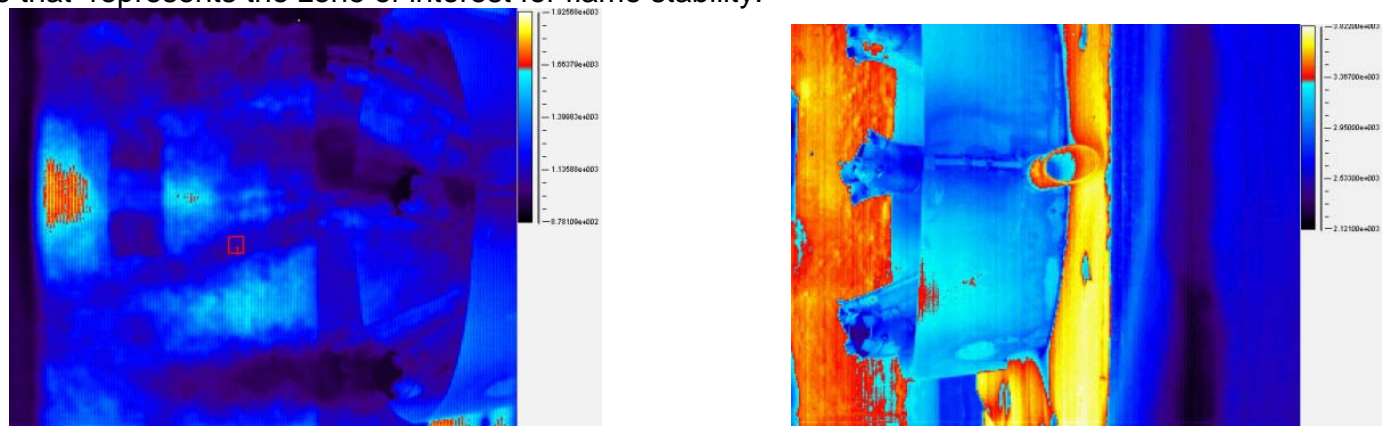

Figure 8: Normal IR view of the flame (left) and $3.9 \mu \mathrm{m}$ filtered view of the flame (right).

The frequency analysis of the maximum intensity present in the red rectangle was performed for different combustion conditions. The measurements were performed for the maximum burner load with methane, and blend 50\%methane$50 \%$ hydrogen, steam injection and exhaust gas recirculation. The results are presented in the figure 9.

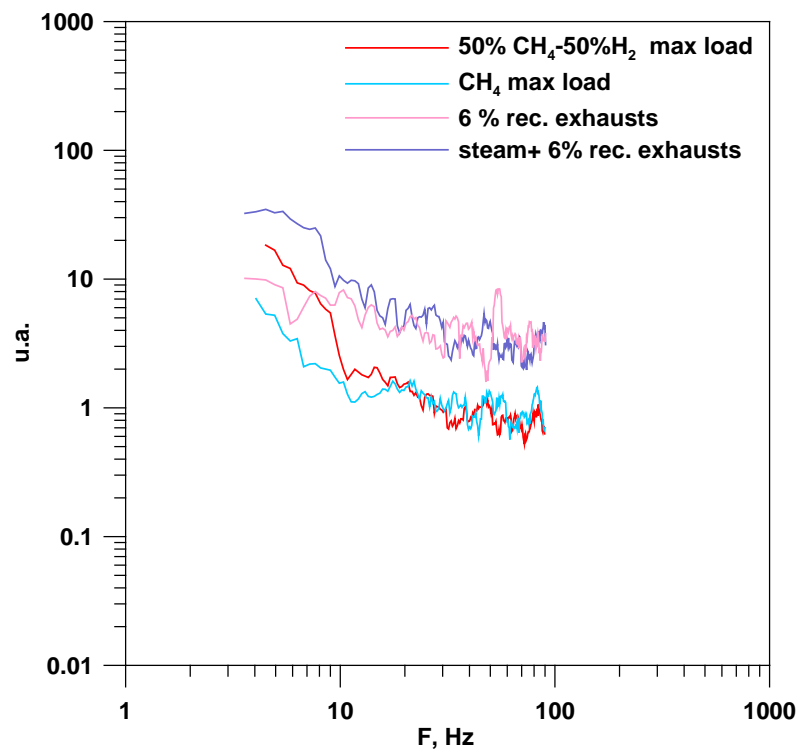

Figure 9: Frequency analysis under different combustion conditions.

We can observe in this figure that the presence of hydrogen did not perturb the flame stability either in term of frequency, either in term of curve slope, namely in term of the turbulence scale. Moreover, the addition of water steam and recirculation exhausts lead to a slope reduction, and thus to the turbulence intensity. In this combustion application a very special design of the burner was adopted in order to obtain a wide operative flexibility regarding fuel characteristics. A fuel/exhaust gas dilution was made internally and lead to a strong reduction of the flame front intensity as well as operating with high Hydrogen content. Further external dilution has an effect in the NOx emission reduction. 
Further experiments were performed on the coal burner (CB) changing the fluid dynamic conditions, namely primary and secondary air blades. The operative conditions are presented in the table IV. The test was made using a pulverized sub bituminous South African coal.

\section{Table IV: Different burner set up}

\begin{tabular}{|c|c|c|c|}
\hline Condition number & Time & Primary air swirl & Secondary air swirl \\
\hline 1 & $15 \mathrm{~h} 39$ & $25^{\circ}$ & $35^{\circ}$ \\
\hline 2 & $16 \mathrm{~h} 07$ & $25^{\circ}$ & $45^{\circ}$ \\
\hline 3 & $16 \mathrm{~h} 45$ & $35^{\circ}$ & $45^{\circ}$ \\
\hline 4 & $17 \mathrm{~h} 23$ & $45^{\circ}$ & $45^{\circ}$ \\
\hline 5 & $17 \mathrm{~h} 47$ & $40^{\circ}$ & $45^{\circ}$ \\
\hline
\end{tabular}

The indicative burner position is tagged by green circle on figure 10 . The white rectangle part represents the refractory wall seen in the window.

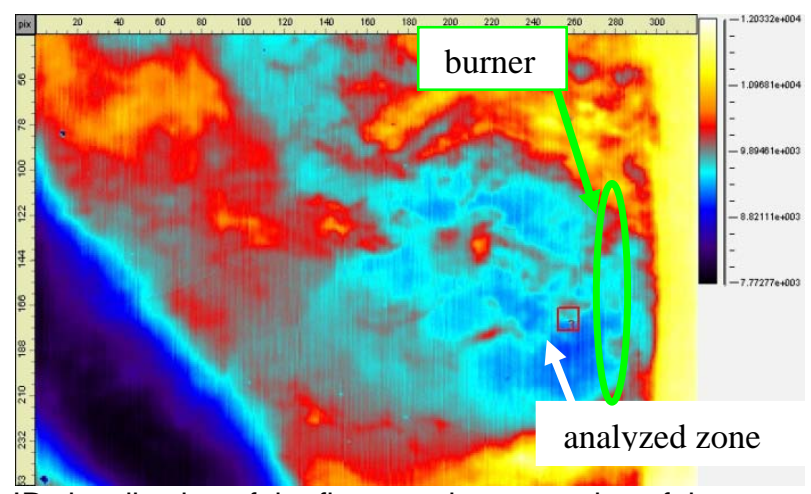

Figure 10: IR visualization of the flame and presentation of the zone of interest.

In order to obtain information about the flame stability, frequency analysis was performed. The zone of interest was chosen close to the burner exit and is represented by the red rectangle on figure 10. In fact, the flame intensity close to the burner strongly affect the behaviour of the flame and the unburnt emission. The temporal evolution of the maximum intensity measured in the rectangle was analyzed. Then the FFT of the signal was preformed and the results are presented in figure 11. 


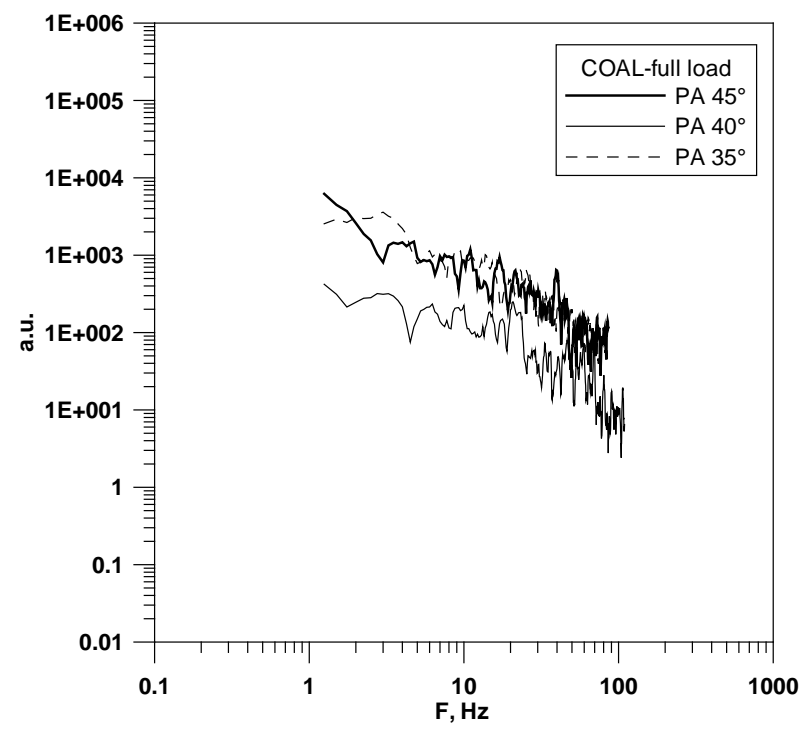

Figure 11: frequency analysis for coal burner.

We can observe the presence of a frequency peak at $40 \mathrm{~Hz}$ in the case of primary air set at $35^{\circ}$, while for PA at $40^{\circ}$ the frequency shift down at $20 \mathrm{~Hz}$ (fig. 11). For all the condition, the slopes of the FFT plots are similar, thus indicating a similar level of turbulence. The absolute signal intensity depends on the flame emission and consequently on the temperature. So, we can hypothesize that in the case of a PA swirl of $40^{\circ}$, the temperature is lower than in the other cases. Moreover, the high sensitivity measurements allow to individuate high and low temperature/emissivity scatterers, namely hot gases $\left(\mathrm{CO}_{2}\right)$ and small particles (coal, particulate).

\section{Conclusion}

A new diagnostic tool was applied to spatially characterize combustion fluctuations. The tool based on FAst IR Imaging of flames was applied on two different types of gas turbine burners and on two traditional industrial burners varying the fluid dynamic conditions.

- GT burners evidenced oscillation at low frequencies around $25 \mathrm{~Hz}, 100 \mathrm{~Hz}$ and at higher frequencies up to several kHz. Typical frequencies bias toward combustion were identified. The investigations also evidenced that the typical frequencies shift up while increasing AFR. The FAIRI technique allowed to identify higher frequencies (up to several $\mathrm{kHz}$ ) in the $2 \mathrm{D}$ dimensions. The extension of the technique to a practical Lean Premixed gas turbine gave good results either for frequency analysis of fluctuations, either for the location of the phenomenon of humming.

- On industrial boiler combustion FAIRI allowed to identify on both gas and coal combustion the proper location of the flame root and its better performance in stability. Further information have to be collected on air/fuel mixing and local flame temperature. The technique came out as an interesting tool for further development and investigations.

\section{References}

[1]. L. H. Cowell, K. O. Smith, Journal of Engineering for Gas Turbines and Power, (115) (1993) 554.

[2]. T. B. Gradinger, A.Inauen, R Bombach, B. Kappeli, W. Hubschmid, K.Boulouchos, Combustion and Flame, (3) (2001) 124-149.

[3]. M. Brandt, M. Rachner, G. Schmitz, Combustion Science and Technology, (138) (1998) 313.

[4]. T. S. Snyder, T.J. Rosfjord, J.B. McVey, A.S. Hu, B.C. Schlein., Journal of Engineering for Gas Turbines and Power, (118) (1996) 38.

[5]. A.P. Dowling, S. Hubbard, Proc. Instn. Mech., Part A: (214) (2000) 317.

[6]. K.K. Venkataraman, L.H. Preston, D.W. Simons, B.J. Lee, J.G. Lee, D.A. Santavicca, Journal and Propulsion and Power, (15) No. 6 (1999) 909.

[7]. J.W.S. Rayleigh, The Theory of Sound, Macmillan, New York, 1994. 
[8]. T.C. Lieuwen and V. Yang, , Combustion Instabilities in Gas Turbine Engines, Progress in Astronautics and Aeronautics (210) (2005) 505.

[9]. C. Allouis, F. Beretta, A. Amoresano, Combustion Science and Technology, 180:900-909 (2008)

[10]. D. Vauchelles, Etude de la stabilité et des émissions polluantes des flammes turbulentes de prémélange pauvre à haute pression appliquées aux turbines à gaz, Ph. D. thesis, University of Rouen - CORIA, France, 2004.

[11]. G. Cabot, D. Vauchelles, B. Taupin, A. Boukhalfa, Experimental Thermal and Fluid Science, (28) (2004) 683. 